\title{
Undernutrition among children under five (5) years in the municipalities of Natitingou, Boukoumbé and Toucountouna (NBT Zone) in the Department of Atacora in North West Benin
}

\author{
Marius BIO BOUKO ${ }^{1}$, Abdou Ganiou YESSOUFOU ${ }^{1 *}$, Patrice SANTA KOUESSOPA ${ }^{1}$, Abèbi Karimath YESSOUFOU ${ }^{3}$, \\ Adégnika Amirath ADEBO ${ }^{1}$, Mohamed Mansourou SOUMANOU ${ }^{2}$ and Alphonse SEZAN ${ }^{1}$ \\ ${ }^{1}$ Laboratory of Biomembranes and Cell Signaling, Department of Animal Physiology, Faculty of Science and Technology, University of Abomey-Calavi, \\ BP: 526 Cotonou, Republic of Benin \\ ${ }^{2}$ Reseach Unit in Enzymatic and Food Engineering/ Reseach and Applied Chemistry Laboratory. Polytechnology of Abomey-Calavi School, University \\ of Abomey-Calavi, 01 BP 2009 Cotonou, Républic of Bénin \\ ${ }^{3}$ Pediatric Clinic and Neonatology of Sènadé 06 BP 601 Cotonou, Republic of Benin
}

Received 03 Oct 2018, Accepted 05 Dec 2018, Available online 07 Dec2018, Vol.6 (Nov/Dec 2018 issue)

\begin{abstract}
The purpose of this study is to evaluate the nutritional status of the children under five years of the Municipalities of Natitingou, Boukoumbé, and Toucountouna located in the Department of Atacora in North West Benin. It is a prospective, descriptive and analytical study in which we collected the anthropometric measurements of 600 children and submitted their mothers to a questionnaire. The results show that the three forms of undernutrition are still present with 53\% of stunted children, $75 \%$ of underweight children and $26 \%$ of emaciated children. Moreover, the dietary diversity scores recorded in the surveyed households are mostly low. Determinants identified include diseases, dietary diversity, non-compliance with the principle of exclusive breastfeeding, and poor weaning practices. In sum, the very high level of stunting is indicative of chronic food insecurity. There is therefore an awakening of consciousness of the different actors involved in the fight against malnutrition for an improvement of the nutritional status of children in this area of study.
\end{abstract}

Keywords: Benin, undernutrition, wasting, stunting, underweight, dietary diversity

\section{Introduction}

Malnutrition is defined as the set of disorders / conditions resulting from the deficiency or excess of one or more essential nutrients. (National Protocol for the Management of Acute Malnutrition, 2011). It manifests itself in many forms, from severe undernutrition to overweight and obesity. It affects individuals at all stages of life, from conception to old age, through childhood, adolescence and adulthood (FAO, 2017). Globally, 155 million children under 5 years are stunted and 51.7 million are stunted, with the highest prevalence rates in developing countries (FAO, 2017). . In Benin, 34\% of children in this age group are stunted, $5 \%$ are wasted, and one in five is underweight (MICS, 2014). These forms of undernutrition are disparate at the departmental level. Atacora is one of the most affected departments with a prevalence of $29 \%$ for underweight, 5.5 for wasting and $39 \%$ for stunting (MICS, 2014). Thus, for chronic

*Corresponding author's Contacts: Tél : (00229) 97441045/ (00229) 61788161, ORCID ID: 0000-0001-9703-2217

DOI: https://doi.org/10.14741/ijmcr/v.6.6.15 malnutrition, the prevalence approaches the critical threshold of $40 \%$ in this department, reflecting a serious nutritional situation according to WHO. (OMS, 2006). This high rate is indicative of a situation of chronic food insecurity. In fact, according to the Global Vulnerability and Food Security Analysis (AGVSA, 2017), 33.7\% of households in Atacora have poor and limited food consumption. Moreover, at the communal level, among the five communes of this department with a very high rate of global food insecurity are the three communes of our study area. Despite the intervention of several programs and strategies to combat this scourge, the prevalence of undernutrition remains high in this area. Faced with this situation, we proposed to study the problems of malnutrition in children under five in this area.

\section{Materials and methods}

It is a prospective, descriptive and analytical study that took place from July to October 2017 in the communes of Natitingou, Boukoumbé and Toucountouna located in the 


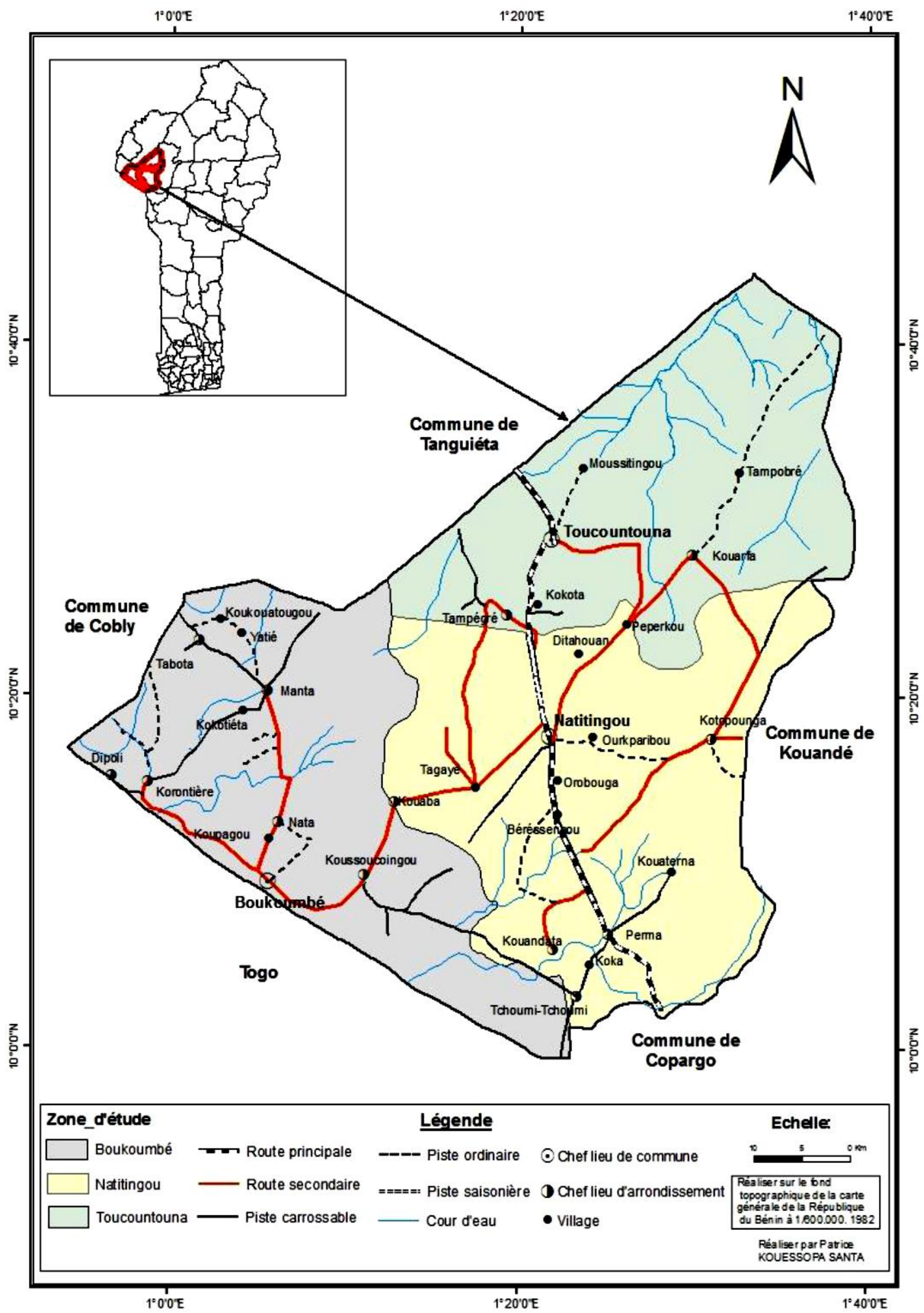

Figure 1: Geographical location of the study area

Atacora Department of North West Benin (Figure 1). The minimum sample size was determined according to Schwartz's (1995) formula. Thus, the anthropometric measurements of six hundred (600) children under 5 years were collected and their mothers submitted to a questionnaire designed for this purpose. 
Assessment of the nutritional status of children

The weight of the children was taken using a Seca-type electronic weighing scale of $150 \mathrm{~kg}$ and the height was measured using a $0.1 \mathrm{~cm}$ precision Shorr height according to the WHO recommendations. . The Weight for Height ( $P$ $/ T)$, Age for Age ( $T / A)$ and Weight for Age ( $P / A)$ indices were calculated using the WHO Antro software, 2006. P / $A$ was used to determine percentage of children underweight ( $P$ / $A$ below -2 SD) and seriously underweight ( $P$ / A below -3 SD). $T$ / A allowed to determine the percentage of children with stunting ( $T$ / $A$ below -2 SD) and significant growth retardation ( $T$ / A below -3 SD). P / T determined the percentage of emaciated children ( $P$ / T below -2 SD) and severely emaciated children ( $\mathrm{P} / \mathrm{T}$ below $-3 \mathrm{SD})$.

\section{Evaluation of dietary diversity}

The dietary diversity of the child was appreciated by the calculation of the dietary diversity score (SDA) of the child. The score was constructed according to the FANTA model (2006) with seven (7) food groups. Children were classified into three (3) categories of dietary diversity: low dietary diversity, where the number of food groups to be consumed per day is 1-2; average dietary diversity, when the number of food groups to be consumed per day is 34 ; dietary diversity, when the number of food groups to be consumed per day is 5-7

\section{Statistical analyzes of the data}

Data processing was done using Excel, WHO Anthro ${ }^{\circledR}$ version 3.2.2, 2011 and SPSS. The Chi2 test in uni-varied analysis was used to look for an association between the different factors and the nutritional status of the children. The higher the chi2 value, the less significant the test $(p<0,05)$.

\section{Ethical considerations}

This survey was authorized by the relevant structures (conf. Memo N ${ }^{\circ} 036 / 2016$ / MS / DDS-AD / ZSN/BZN/CAR/SA).The people involved gave their consent.

\section{Results}

A total of 600 children under the age of 5 years, $44 \%$ of whom were male and $56 \%$ female, were involved in this study. The most represented age group was 12 to 35 years old $(43 \%) .3 / 4$ of the mothers of the children surveyed were farm workers and had no level of education. Of the 600 children, $75 \%$ were underweight, $26 \%$ were emaciated and $53 \%$ were stunted (Figure 2). The distribution curves of the indices (weight for height, weight for age and height for age) in z-score of the surveyed population compared to the WHO reference population curves were shifted to the left (Figure 3, Figure 4 and Figure 5). Factors significantly associated with these three forms of undernutrition were withdrawal and dietary diversity; however, diseases (respiratory infections and fever) were only significantly associated with stunting and wasting.

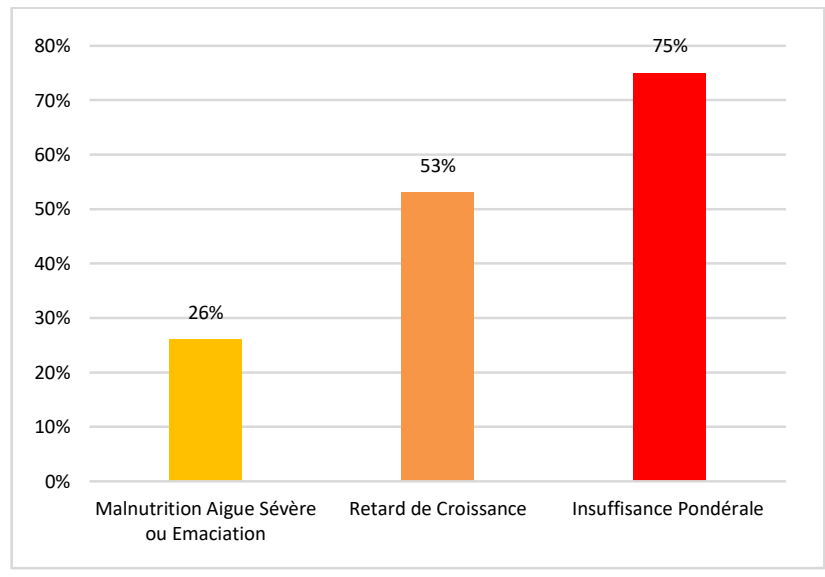

Figure 2: Distribution of children surveyed by nutritional status

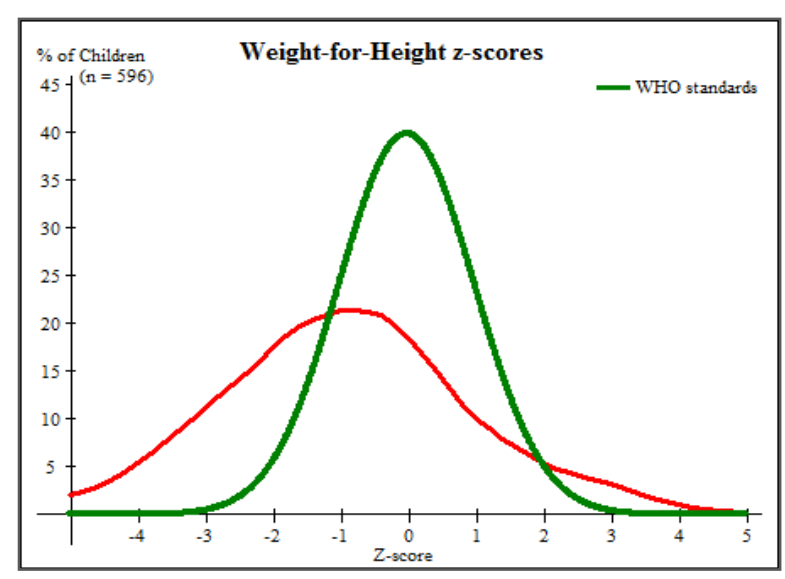

Figure 3: Distribution of the Weight / Size $(P / T)$ index in z-score compared to the WHO reference population 2006

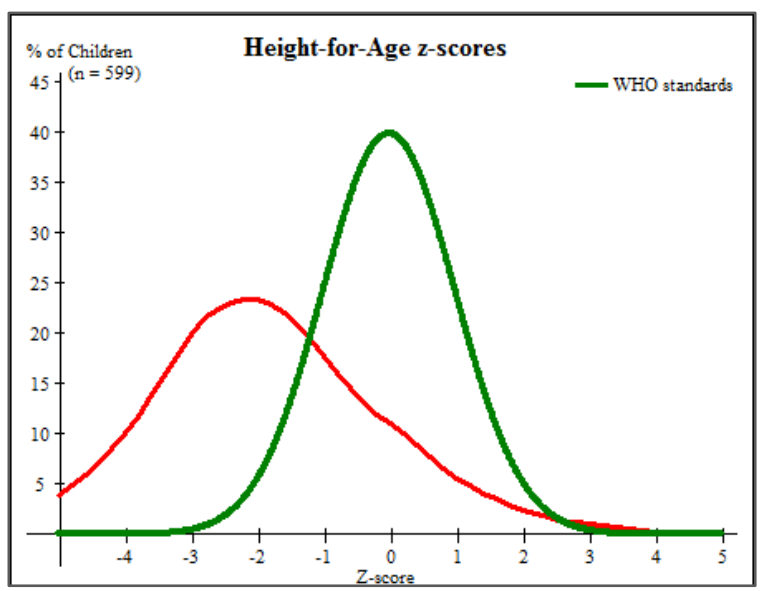

Figure 4: Distribution of the Size / Age (T / A) index in zscore compared to the WHO reference population 2006. 


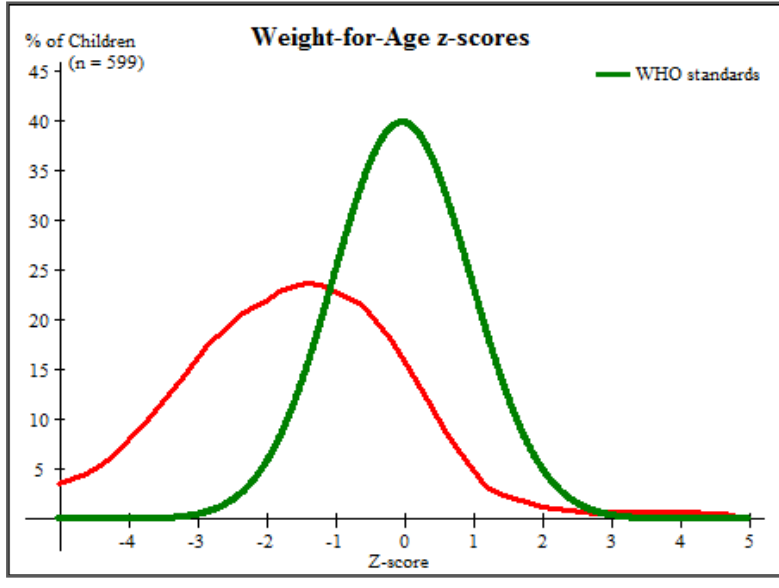

Figure 5: Distribution of the Weight / Age (P / A) index in z-score relative to the WHO reference population 2006

\section{Discussion}

The results showed that $53 \%$ of the children surveyed were stunted; this prevalence is comparable to that obtained in the Pendjari plain as shown by Yessoufou et al., (2014). On the other hand, it is lower than that resulting from the study carried out in the $2 \mathrm{KP}$ zone which is $64.8 \%$ (Bio Bouko et al., 2018). For the other forms of undernutrition, the prevalences obtained were respectively $26 \%$ for wasting and $75 \%$ for underweight. These prevalences are lower than those obtained in the Pendjari plain (Yessoufou et al., 2014). On the other hand, they are well below those obtained in the 2KP zone (Bio Bouko et al., 2018). Moreover, the prevalence obtained for the various forms of undernutrition in the study area are largely above those obtained at the departmental level by several studies (MICS, 2014, AGVSA, 2014). This situation could be explained by the period in which the survey was carried out and the socio-economic characteristics of each zone.

In fact, during the lean season, food becomes more and more expensive on the market, access to food becomes a problem for poor households and the consequence, children under 5 years who are the most vulnerable people can no longer eat their hunger and undernutrition is taking over all its forms. On the other hand, during the post-harvest period, there is abundant availability of food on the market, food becomes financially accessible, agricultural households have enough food in their attics, all of which facilitates household access to food. Children under 5 years are thus less exposed to undernutrition.

In addition, since the socio-economic characteristics are not the same, poverty is unevenly distributed in each zone of Atacora. According to the Global Analysis of Vulnerability and Food Security in Benin (AGVSA, 2017), at the municipality level, five of the nine communes of this Department, had a very high rate of global food insecurity including the municipalities of our study area; in Boukoumbé commune, $42.6 \%$ of households have poor and limited food consumption, in Natitingou $29.8 \%$ and in Toucountouna $23.4 \%$ of households. In the remaining four communes, the food insecurity rate is lower, ranging from $5 \%$ to $15 \%$.

Comparing the different weight / age, weight / height and height / age distribution curves with the respective reference population curves, showed that these curves were shifted to the left relative to the reference curves, which reflects a state of less satisfactory than that of the reference population evoking a tendency to a state of under-nutrition as in the Pendjari plain (Yessoufou et al., 2014) and in the communes of 2KP (Bio Bouko et al., 2018). This state of undernutrition recorded in the study population compared to the reference population could be explained as well by the insufficient food intake ( $p$ $<0.05)$, by the bad practices of weaning ( $p=0.002$ ), low dietary diversity score $(p=0.01)$, and diseases such as acute respiratory infections, diarrhea and fever $(p<0,05)$

\section{Conclusion}

Undernutrition in all its forms is widespread in the communes of Natitingou, Boukoumbé and Toucountouna. It is due to poor weaning practices, difficult access to food and diseases. There is therefore an awakening of consciousness of the different actors involved in the fight against malnutrition for an improvement of the nutritional status of children in this area of study.

\section{References}

[1]. Agvsa (2017) : Analyse Globale de la Vulnérabilité et de la Sécurité Alimentaire. PAM et INSAE, République du Bénin, $219 \mathrm{p}$

[2]. Agvsa (2014) : Analyse Globale de la Vulnérabilité et de la Sécurité Alimentaire. PAM et INSAE, République du Bénin, $146 \mathrm{p}$

[3]. Fanta. (2006): Working Group on Infant and young child feeding Indicators. Developing and validating simple indicators of dietary quality and energy intake of infants and young children in developing countries: summary of findings from analysis of 10 data sets. Washington, DC: the food and Nutrition technical Assistance Project and Academy for Educational Development, pp 192-199

[4]. FAO. (2017) : L'état de la sécurité alimentaire et de la nutrition dans le monde. Renforcer la résilience pour favoriser la paix et la sécurité alimentaire Rome, FAO.144 p

[5]. Marius Bio Bouko, Abdou Ganiou Yessoufou, Justin Behanzin Abèbi Karimath Yessoufou And Alphonse Sezan (2018): Prevalence of malnutrition among children under 5 years in the municipalities of $2 \mathrm{KP}$ (Kerou, Kouande, And Pehunco) in northern Benin, International Journal of Advanced Research 6(1), pp 1293-1298

[6]. Mics (2014) : Enquête par grappes à indicateurs multiples, rapport final INSAE, 2015, Bénin, 247p

[7]. Oms (2006): Organisation Mondiale pour la Santé, les indice Anthropométrique, construction enjeux et analyse statistiques, $46 p$

[8]. Protocole Nationale de Prise en Charge de La Malnutrition Aigüe (2011) : Direction de la Santé de la Mère et de l'Enfant, 12 p

[9]. Schwartz (1995): Guide du chercheur et lignes directives pour l'évaluateur d'un mémoire ou d'une thèse en sciences humaine, d'OGOUWALE. et al. $82 \mathrm{p}$

[10]. Yessoufou A. G; Ahopke M.; Behanzin J.; KountoriR.; Senou M.; Sezan A. (2014): Prévalence de la malnutrition aigüe chez les enfants de moins de cinq ans dans la plaine de pendjari au nord ouest du Bénin ; J. Rech. Sci. Univ. Lomé ( TOGO) Série A 16(3) : pp $62-78$ 